\title{
Inside UK Universities: Staff mental health and wellbeing during the coronavirus pandemic
}

Isla Dougall, Mario Weick and Milica Vasiljevic Dept. of Psychology Durham University June 2021 


\section{About}

Isla Dougall is a PhD student in the Department of Psychology, Durham University. Isla's research examines social class differences in wellbeing.

Dr Mario Weick and Dr Milica Vasiljevic are Associate Professors of Quantitative Social Psychology at Durham University. Mario's research focuses on power and status relations, and Milica's research focuses on developing interventions to reduce health inequalities.

Preparation of this report was supported by an Equality, Diversity, and Inclusion (EDI) PhD studentship awarded to Isla Dougall, funded by the Department of Psychology, Durham University.

This report is published as a stand-alone piece aimed at both academic and non-academic readers. Findings arising from this research will inform a future peer-reviewed publication focused on social class and wellbeing in higher education, building on prior work by the authors (Dougall, Weick, \& Vasiljevic, 2021).

A visual abstract illustrating some key findings can be found in the PsyArXiv Supplemental Materials, and downloaded from https://osf.io/ytvs6/.

Correspondence regarding this report should be addressed to behavioural.science@durham.ac.uk.

How to cite this work:

Dougall, I., Weick, M., \& Vasiljevic, M. (2021, June 22). Inside UK Universities: Staff mental health and wellbeing during the coronavirus pandemic. Retrieved from psyarxiv.com/23axu 


\section{Contents}

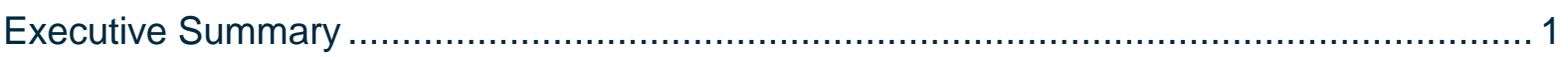

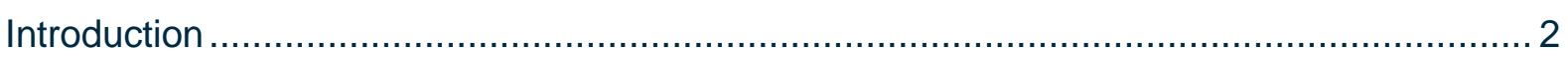

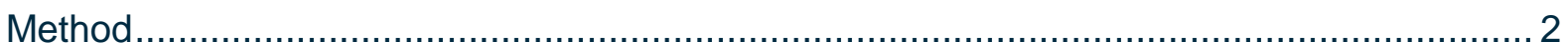

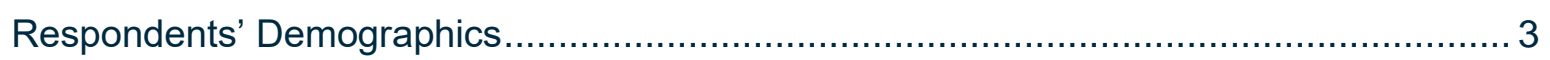

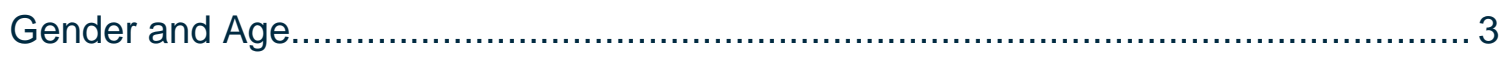

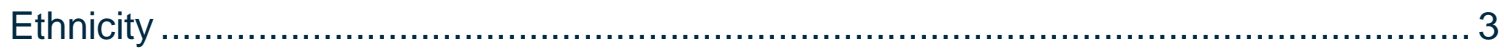

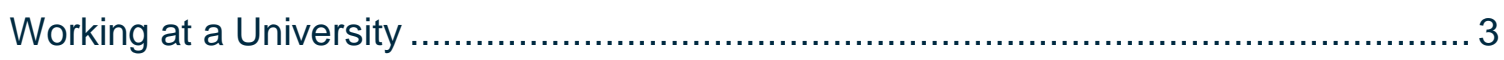

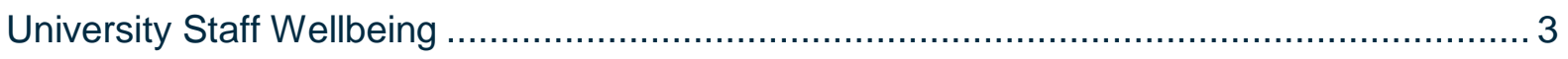

Wellbeing Compared to the National Average …........................................................ 3

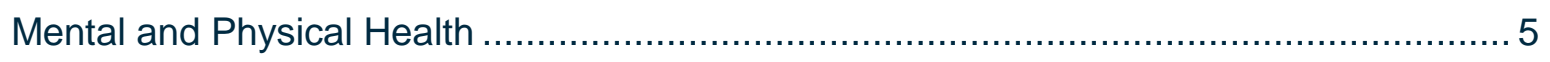

Mental and Physical Health by Employment Status ………......................................

Mental Health by Hours Worked ................................................................... 6

Mental and Physical Health by Ethnicity.................................................................. 7

Mental and Physical Health by Subjective Socio-Economic Status ............................... 8

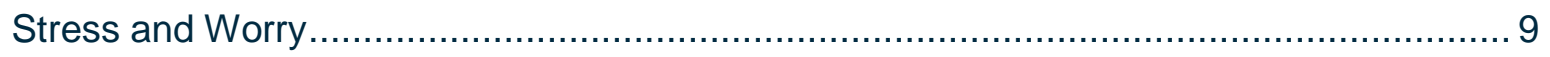

Stress and Worry by Caring Responsibilities and Gender ......................................... 9

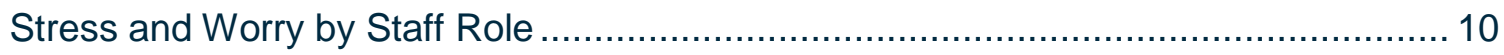

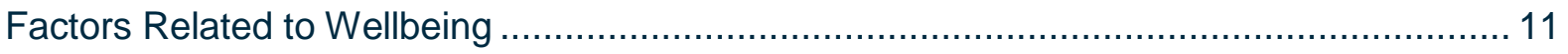

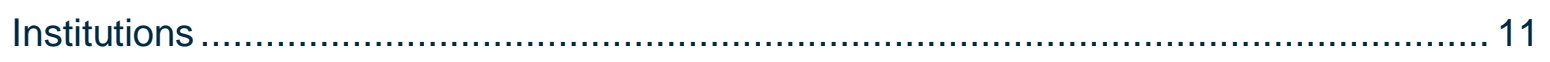

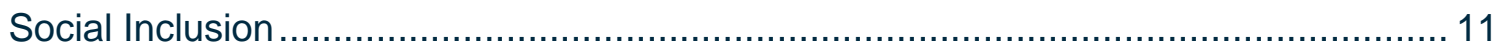

Alignment between Skills and Task Demands....................................................... 11

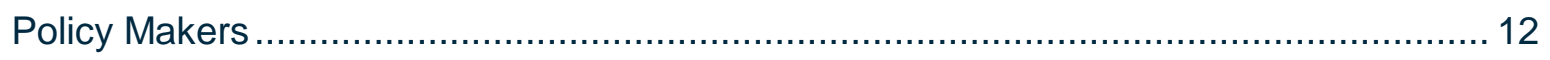

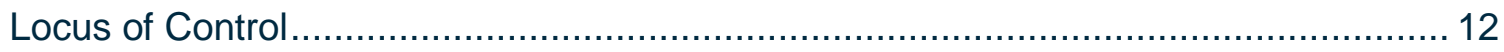

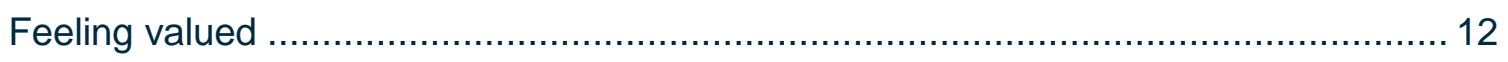

Practice and Policy Implications .............................................................................. 13

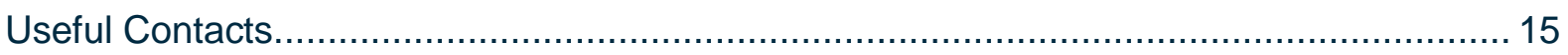

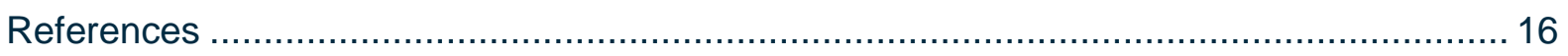




\section{Executive Summary}

This report documents the mental health and wellbeing of university staff during the coronavirus pandemic, using survey data collected online in March 2021 from 1,182 staff employed across 92 UK universities. Overall, the survey data suggest that university staff are grappling with high levels of poor mental health and wellbeing:

- One in two university staff reported experiencing chronic emotional exhaustion (55\%), worry (53\%), and stress (51\%) during the academic year 2020/21.

- Half of the staff surveyed (47\%) described their mental health as poor.

- Over a third of staff members reported low life satisfaction (36\%).

- More than a quarter of staff reported feeling as if the things they did in their lives were not worthwhile (27\%).

- One in two staff members experienced high levels of anxiety (50\%) - 1.5 times higher than the national average ${ }^{1}(32 \%)$.

- One in three university staff reported low levels of happiness (33\%) compared with a national average ${ }^{1}$ of one in seven (14\%).

In this report, we explore factors that may alleviate the burden of poor mental health and wellbeing amongst HE staff. Factors that fall more within the remit of institutions include social inclusion and the alignment between skills and task demands. Factors that fall more within the remit of government and policy makers include autonomy and the value that is placed on universities and their staff.

In publishing this report, we hope institutional leaders and policy makers will recognise the urgent need to improve staff mental health and wellbeing. As we approach another academic year impacted by Covid-19 and universities in England brace themselves for funding cuts in the next spending review, action is needed to prevent a further deterioration in staff mental health and wellbeing.

\footnotetext{
${ }^{1}$ National average as reported by the Office for National Statistics in their Opinions and Lifestyle Survey from data collected between $24^{\text {th }} \mathrm{Feb}$ and $21^{\text {st }}$ Mar 2021.
} 


\section{Introduction}

Amongst staff within UK universities, mental health and wellbeing is notoriously poor.

Surveys carried out before the coronavirus pandemic have shown that UK-based university staff face high levels of stress and burnout, and low levels of job satisfaction (Guthrie et al., 2017; Kinman \& Wray, 2013; Morrish, 2019; Padilla \& Thompson, 2016; Shin \& Jung, 2014; Tytherleigh et al., 2007; Watts \& Robertson, 2011).

Several factors have been attributed to the experience of university staff, including but not limited to, an academic culture that values workaholism (Hogan, 2016), and the proliferation of a lack of job support and unsatisfactory governance (Barkhuizen et al., 2014; Erickson et al., 2020; Tytherleigh et al., 2007). Perhaps overarching all these factors is the increased pressure to be "doing more with less" in the wake of the marketisation of the higher education sector (Kinman, 2014).

Within the last year, this picture has become more complex with the arrival of the coronavirus. For university staff, the pandemic signalled significant changes to the delivery of teaching and student support, which required staff to work remotely and adopt online teaching. These changes were implemented at a time when the mental wellbeing of people around the UK was suffering as a result of the pandemic and subsequent lockdowns (Jia et al., 2020), and placed increased demands on a group already at risk of poor mental health (Kinman et al., 2006).

Considering this, it is vital to collect data on the mental health and wellbeing of university staff and examine the breadth and depth of the problem. This report presents an effort to shed a timely light onto the experiences of university staff during the pandemic and considers some (selected) factors that may underpin the problem.

\section{Method}

We had a sample of 1,182 university staff who took part in a 10-minute online survey between 23rd Feb and 18th March 2021. The university staff were employed across 92 universities; from 52 universities established pre-1992 and 40 universities established post1992. Seventy-six percent $(N=899)$ of respondents were employed by pre-1992 institutions and $23 \%(\mathrm{~N}=273)$ were employed by post-1992 institutions.

University staff were recruited online through circular emails disseminated via university departments, mailing lists, and via social media. As compensation, survey respondents could enter a prize draw to win up to $£ 50$ of shopping vouchers. The study received ethical approval from Durham University Department of Psychology Ethics Sub-committee. 


\section{Respondents' Demographics}

\section{Gender and Age}

Of the university staff taking part, $68 \%$ identified as women $(N=802), 30 \%$ identified as men $(N=359), 1 \%$ identified as neither men nor women $(N=11)$, and $1 \%$ did not disclose their gender identity $(N=10)$. The mean age of respondents was 43.78 years $(S D=10.87)$.

\section{Ethnicity}

Considering ethnicity, $92 \%$ of respondents self-identified as White $(N=1083), 3 \%$ as mixed or multi-ethnic ( $N=36), 3 \%$ as Asian or Asian British $(N=31), 1 \%$ as belonging to other ethnicities $(N=15)$, and the remaining respondents did not disclose their ethnic background $(1 \%, N=13)$.

\section{Working at a University}

Seventy-three percent $(73 \%)$ of respondents were Academic staff $(N=860), 23 \%$ of respondents were Professional Services staff $(N=271)$, and $4 \%$ indicated that they did not fall into either of these categories $(N=49)$. The majority $(75 \%)$ of respondents were on permanent contracts $(N=890)$, with $22 \%$ on fixed-term or temporary contracts $(N=258)$, and $3 \%$ on zero-hours contracts $(N=31)$.

Seven percent of respondents worked up to 20 hours in an average working week $(7 \% ; N=$ 84), 43\% worked between 21 and 40 hours $(N=503), 42 \%$ worked between 41 and 60 hours $(N=498)$, and $8 \%$ worked over 60 hours $(N=91)$. In this survey, which included staff working part time, more than one-in-five (22\%) respondents worked over 50 hours each week, which is in excess of the 48 hour weekly limit set by the UK Government's Working Time Directive.

\section{University Staff Wellbeing}

All comparisons discussed in this report are statistically significant (at the 95\% level) unless stated otherwise.

\section{Wellbeing Compared to the National Average}

Respondents were asked to rate their levels of anxiety and happiness 'yesterday'. These questions were taken from the Office for National Statistics (ONS) Opinions and Lifestyle Survey (ONS, 2021). For happiness, scores were considered 'low' if respondents reported a score of 0 to 4 , on a scale of 0 to 10 . For anxiety, scores were considered 'high' if respondents reported a score of 6 and above. This is in line with the categories used in the ONS Opinions and Lifestyle Survey. 
Figure 1 shows the present survey data plotted against the national average as reported by the ONS Opinions and Lifestyle Survey from data collected during the same time period $\left(24^{\text {th }}\right.$ Feb - $21^{\text {st }}$ March 2021).

\section{Figure 1}

Rates of happiness and anxiety among university staff compared with the national average as reported by the ONS Opinions and Lifestyle Survey.

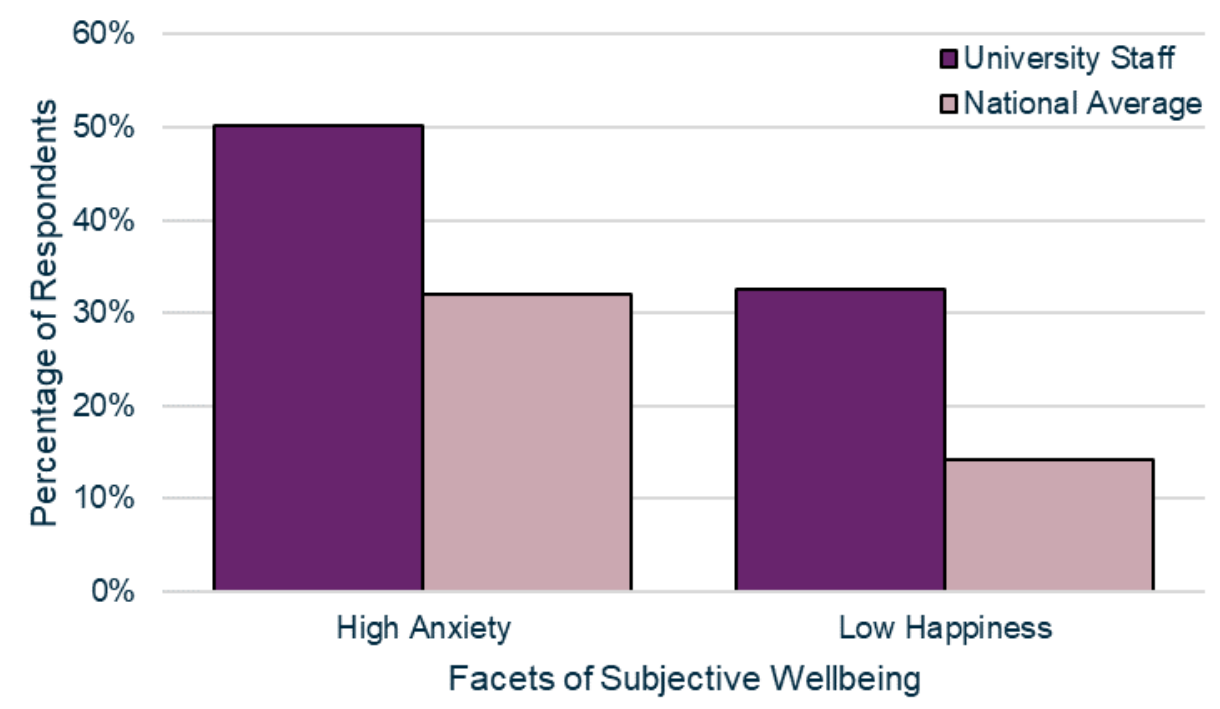

Half of university staff reported having high anxiety - 1.5 times as many as ONS respondents (50\% and $32 \%$, respectively). Furthermore, one-in-three university staff reported low levels of happiness (33\%) compared with one-in-seven (14\%) ONS respondents.

Respondents were also asked to rate their levels of life satisfaction and whether they felt like the things they did in their lives were worthwhile. These questions were adapted from the ONS Opinions and Lifestyle Survey. While the ONS survey gauges respondents' experiences 'overall', the present survey gauged respondents' experiences 'since the start of the academic year'. As above, and in line with the ONS Opinions and Lifestyle Survey, scores were considered 'low' if respondents reported a score of 0 to 4 , on a scale of 0 to 10 . More than one-in-three (36\%) university staff members reported having low life satisfaction, and more than one-in-four (27\%) did not feel things in their lives were worthwhile since the start of the academic year. Figure 2 illustrates these data along with responses collected from ONS respondents, $12 \%$ of whom reported experiencing low life satisfaction, and $9 \%$ of whom reported that they did not feel things in their lives were worthwhile. 


\section{Figure 2}

Rates of life satisfaction and feeling worthwhile among university staff, and the national average as reported by the ONS Opinions and Lifestyle Survey.

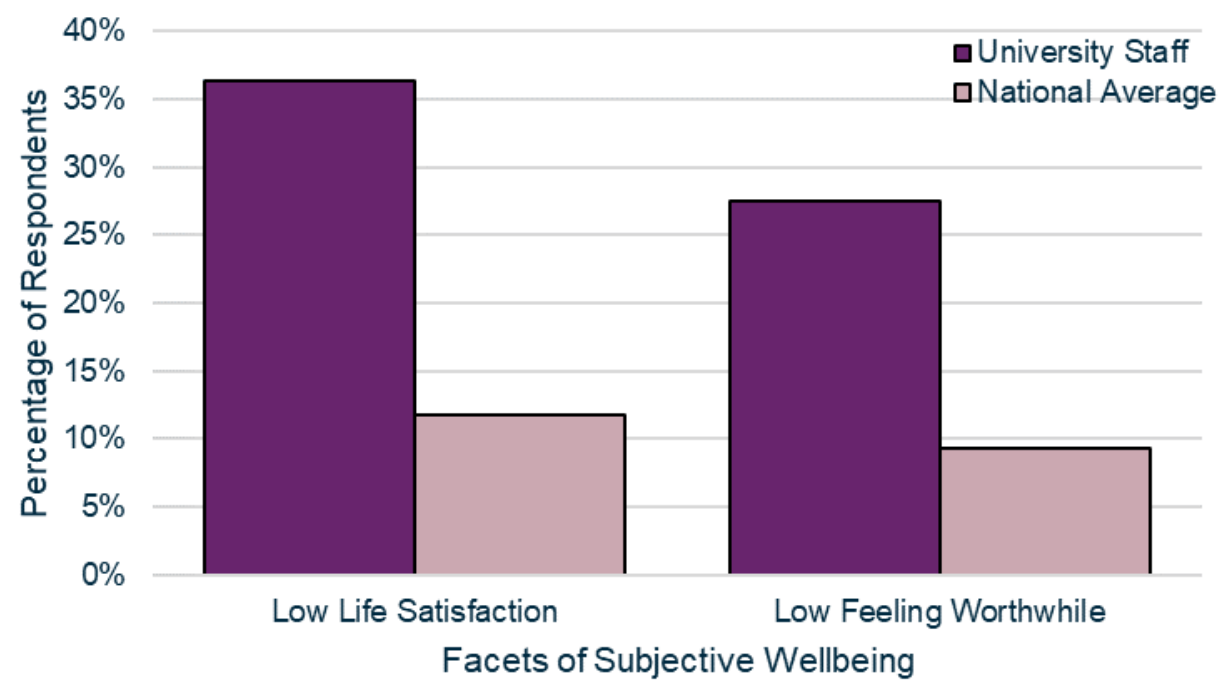

\section{Mental and Physical Health}

Respondents were asked to rate their overall mental and physical health on a 0-10 scale. Again, we categorised responses ranging from 0 to 4 as an indication of poor health. Almost half of respondents reported their mental health to be poor (47\%), and $28 \%$ reported their physical health to be poor.

\section{Mental and Physical Health by Employment Status}

Rates of poor mental and physical health varied with respondents' employment status. Of those employed on a permanent contract, $45 \%$ reported poor mental health compared with $53 \%$ of those on fixed-term or hourly contracts. However, rates of poor physical health among those on permanent contracts $(29 \%)$ were not significantly different from those on fixed-term or hourly contracts (25\%). See Figure 3. 


\section{Figure 3}

Percentage of respondents with poor mental and physical health by employment status.

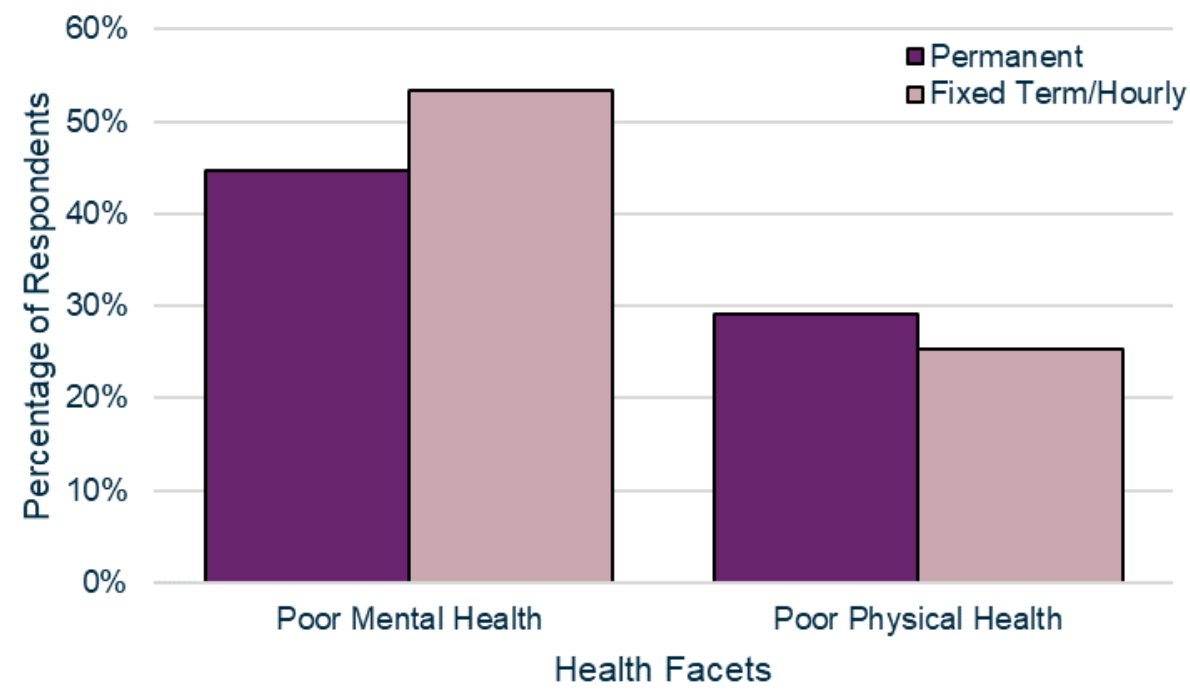

\section{Mental Health by Hours Worked}

We explored how the average number of hours worked each week relates to respondents' mental health. As shown in Figure 4, the lowest proportion of staff reporting poor levels of mental health was observed amongst respondents working 11-20 hours per week (38\%), and the highest proportion amongst respondents working in excess of 50 hours (53\%-64\%). For every additional 10 hours worked beyond 31-40 hours, the proportion of staff reporting poor mental health increased by around $5 \%$. 


\section{Figure 4}

Mental health by average weekly working hours since the beginning of the 2020/21 academic year.

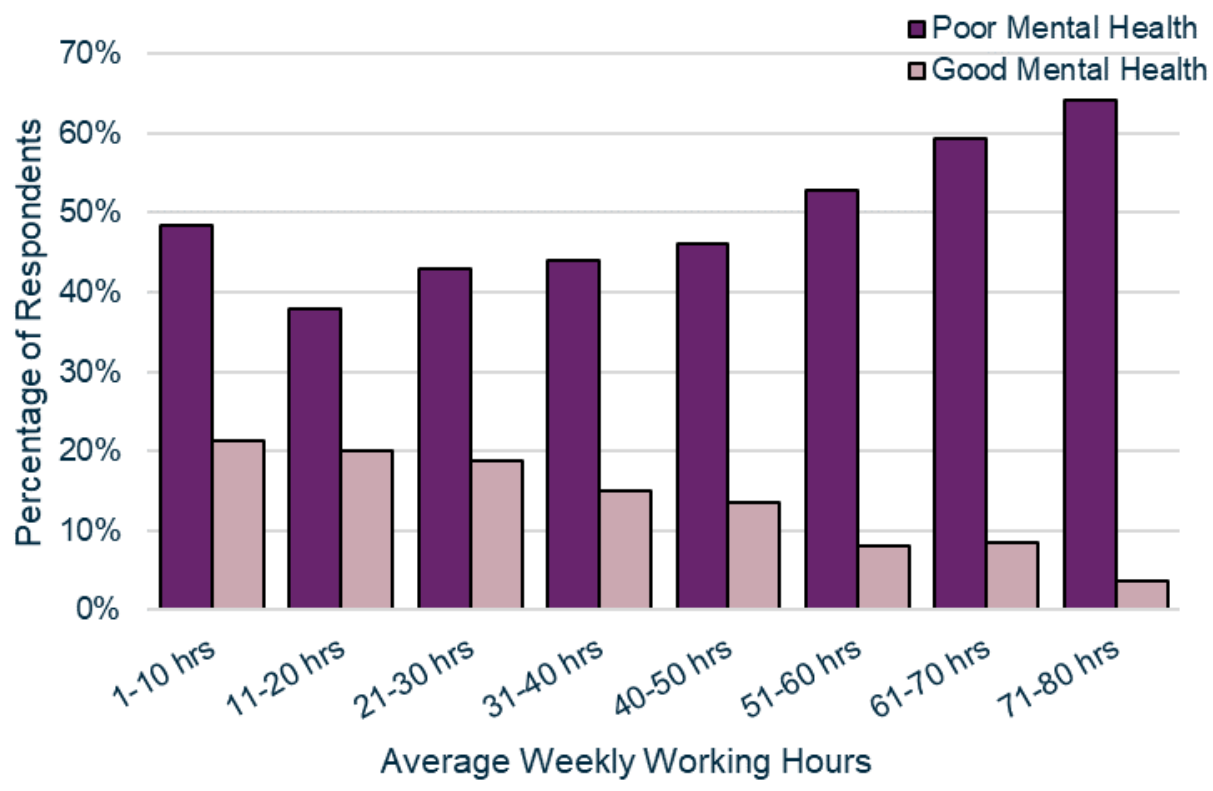

\section{Mental and Physical Health by Ethnicity}

Due to a low number of respondents from ethnic minority groups, we collapsed respondents' ethnicity into two groups; white and all other ethnic groups combined. A greater proportion of respondents from ethnic minority groups reported having poor mental health (62\%) compared with white respondents (45\%). The proportion of respondents from ethnic minority groups reporting poor physical health (36\%) was not significantly different from the proportion of white respondents (27\%). See Figure 5. 


\section{Figure 5}

Percentage of respondents with poor mental and physical health by ethnicity.

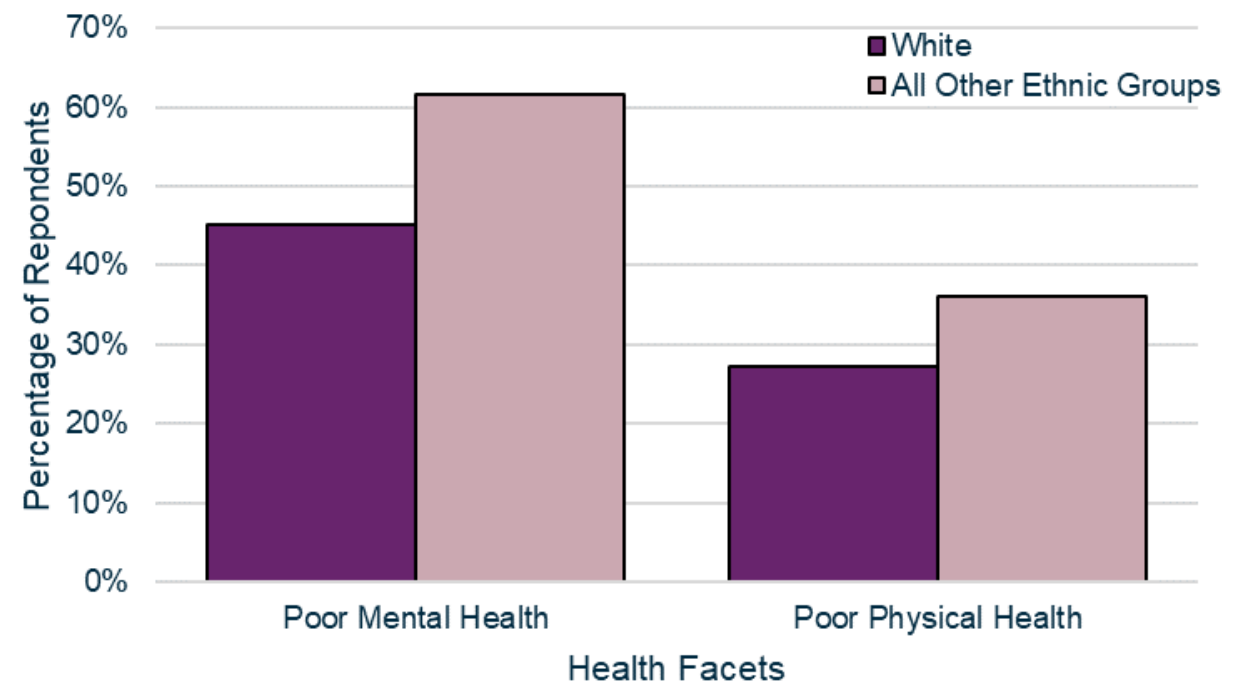

\section{Mental and Physical Health by Subjective Social Status}

To measure subjective social status, we asked respondents to indicate where they thought they stood in society in terms of their economic, social and cultural capital, from 0 (worst off) to 100 (best off). For the analysis, we created an average score from these three measures, and respondents were divided into three groups representing low (0-33) medium (34-66) and high (67-100) subjective social status groups (similar to Bosma et al., 2015; Chen et al., 2012). As can be seen in Figure 6, among respondents with low subjective social status, $73 \%$ reported poor mental health since the lockdown began, compared with $37 \%$ of respondents with high subjective social status (see Dougall et al., 2021, for a recent study exploring the link between social class and mental health and wellbeing amongst university staff). Considering physical health, $48 \%$ of low subjective social status respondents reported poor physical health since the lockdown began compared with $19 \%$ of high subjective social status respondents. 


\section{Figure 6}

Percentage of respondents with poor mental and physical health by subjective social status.

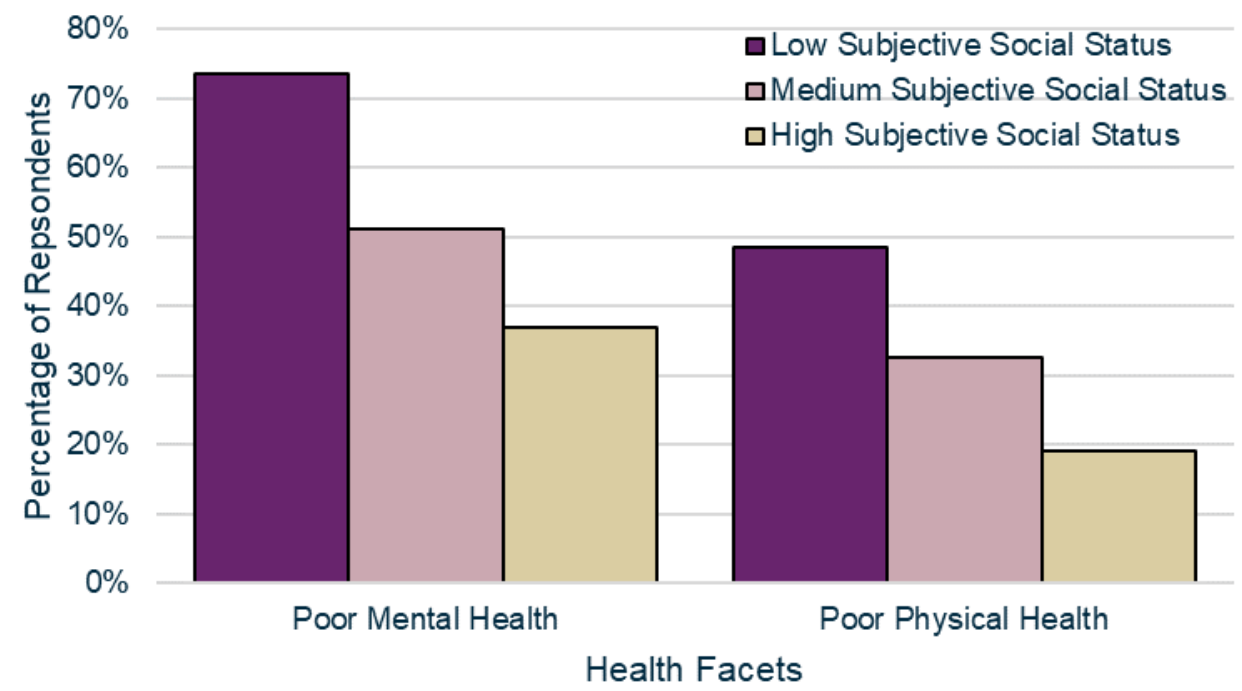

\section{Stress and Worry}

Respondents were asked to consider how often they felt emotionally exhausted, stressed, and worried since the start of the academic year (ca. 5-6 months). Reported states were considered 'chronic' if respondents scored 8 or above, on a scale of 0 (never) to 10 (always). Over half of respondents had experienced chronic emotional exhaustion (55\%), worry (53\%) and stress $(51 \%)$ since the beginning of the academic year.

\section{Stress and Worry by Caring Responsibilities and Gender}

In this section, due to the low number of respondents that identified as neither men nor women, we have only reported the results for two gender identities: men and women.

We asked respondents whether they currently had any caring responsibilities; this included caring for any adult or any child, with or without additional needs. Forty-six percent of women and $42 \%$ of men reported having caring responsibilities.

Among women, rates of chronic emotional exhaustion were higher among those with caring responsibilities (68\%) compared to those without (54\%). A similar pattern was seen among men: $51 \%$ with caring responsibilities experienced chronic emotional exhaustion compared to $38 \%$ of those without.

Considering chronic stress and worry, there were no significant differences between women with caring responsibilities (58\%-59\%) and those without (54\%-56\%). There were also no significant differences among men, with rates ranging between $43 \%-48 \%$ for those with caring responsibilities, and $40 \%$ for those without. See Figure 7. 


\section{Figure 7}

Percentage of respondents reporting chronic emotional exhaustion, worry and stress by caring responsibilities and gender.

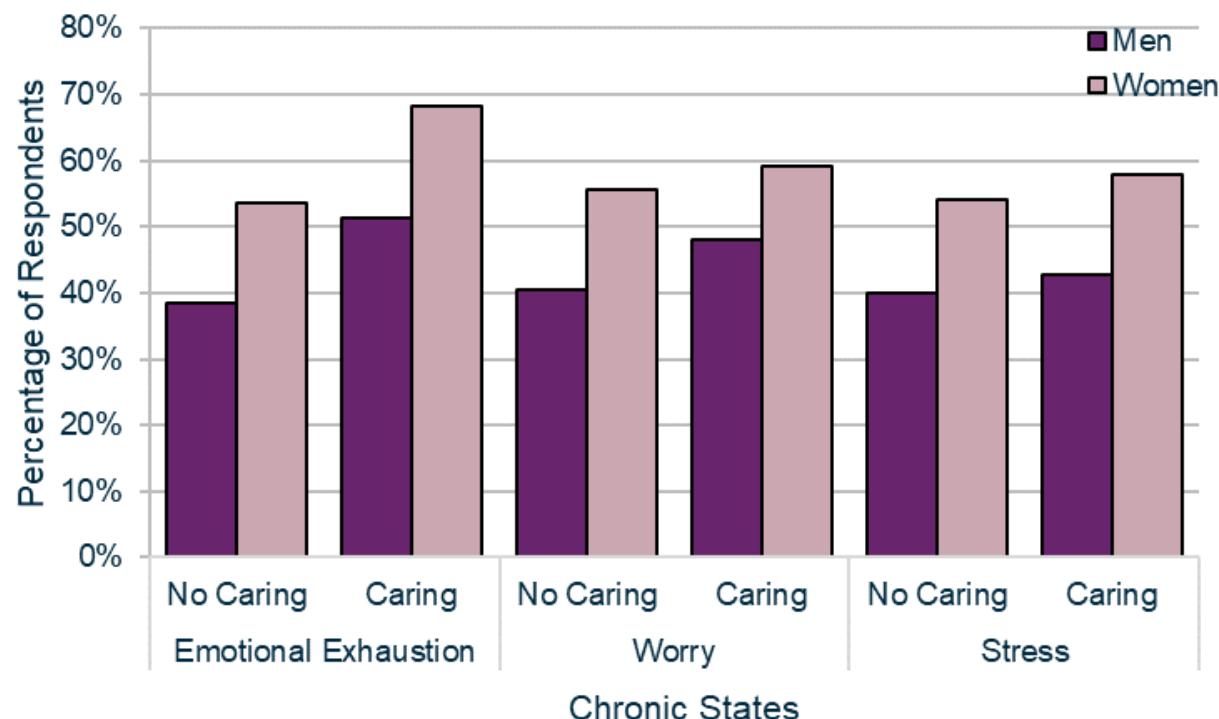

\section{Stress and Worry by Staff Role}

The proportion of respondents who experienced chronic emotional exhaustion was lower among those in Professional Services roles (49\%) compared to those in combined Research and Teaching roles (62\%). Similarly, for experiences of chronic stress, the proportion of respondents was lower among those in Professional Services roles (42\%) compared to those in Research-only roles (59\%), and those in Research and Teaching roles (57\%). The proportion of respondents who had experienced chronic worry did not significantly differ by staff role, ranging from $46 \%$ among those in Professional Services roles to $57 \%$ among those in Teaching-only roles. See Figure 8. 


\section{Figure 8}

Percentage of respondents reporting chronic emotional exhaustion, worry and stress by staff role.

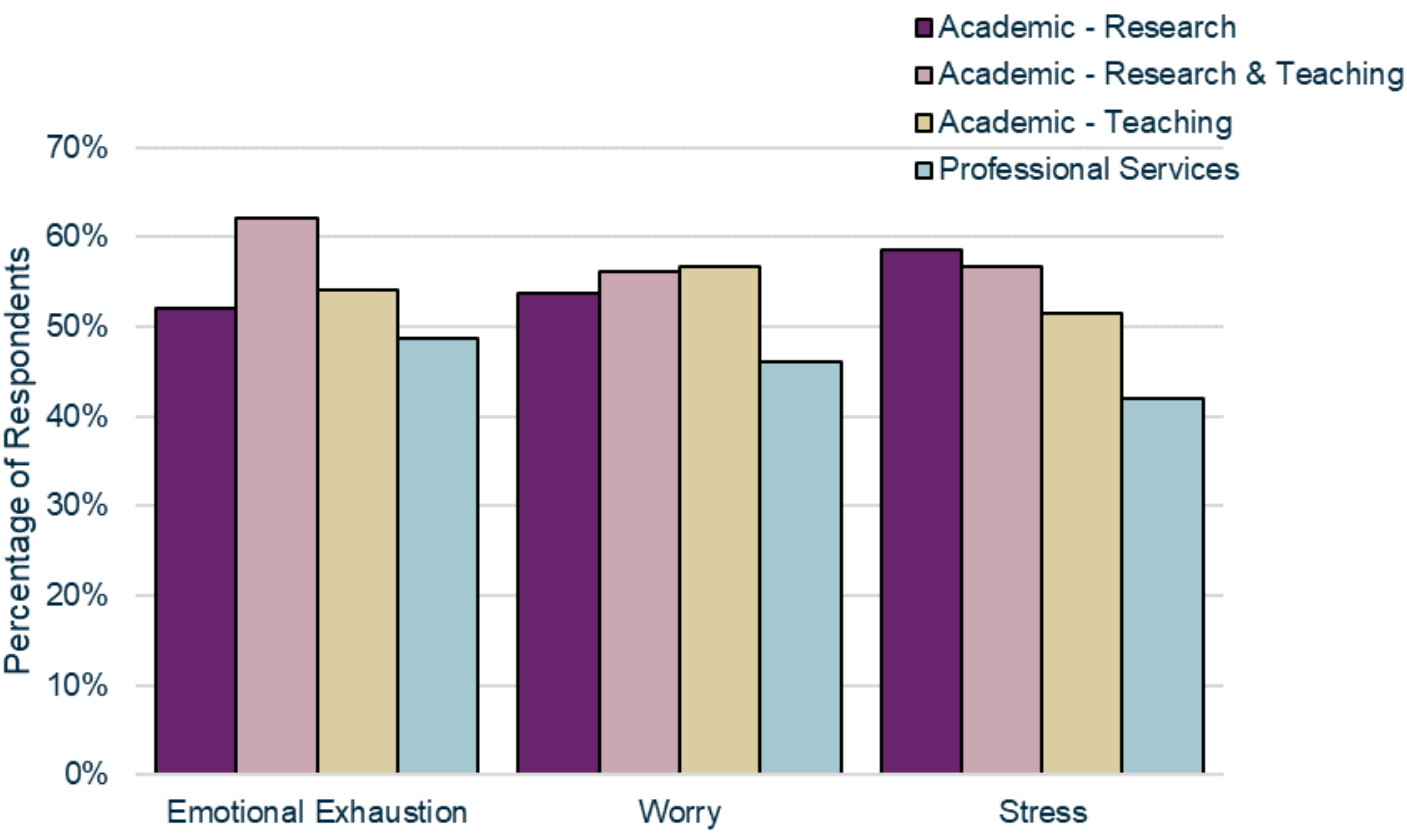

Chronic States

\section{Factors Related to Wellbeing}

We also sought to explore factors that may underpin this pattern of poor mental health and wellbeing amongst university staff members (see also Dougall et al., 2021). Below, we separate those factors into aspects that fall more within the remit of institutions, and aspects that fall more within the remit of government and policy makers.

\section{Institutions}

\section{Social Inclusion}

Three quarters of respondents felt included at work (75\%). Feelings of inclusion were related to wellbeing: respondents who felt more socially included reported better mental health than those who did not. For example, we asked respondents whether they felt like their colleagues were willing to be friends with them. For those who did believe this to be true, scores for mental health were higher (5.1 out of 10) than for those who did not (2.5 out of 10).

\section{Alignment between Skills and Task Demands}

We also examined feelings of competence and achievement as an indication of the alignment between staff members' skills and task demands. More than a third of respondents did not feel competent at work (36\%). Staff who felt competent had better 
mental health than those who did not. For example, we asked respondents whether they had been given a chance to show what they are capable of since the start of the academic year. Among respondents who had been given this opportunity, mental health was higher (6.4 out of 10 ) compared to those who had not (2.9 out of 10).

\section{Policy Makers}

We also probed respondents' beliefs about views and actions of policy makers. In our survey, we defined policy makers as people responsible for creating UK policies and regulations. For example, members of the Government, MPs, Lords, Scientific Advisers, civil servants, advisory staff, etc.

\section{Locus of Control}

Four-in-ten respondents (45\%) expressed having low levels of personal control, and the majority of respondents (71\%) thought their lives had been more strongly influenced by policy makers than by themselves. As shown in Figure 9, the more respondents thought they were in control as opposed to policy makers, the better their mental health.

\section{Figure 9}

Locus of control (policy makers vs. self) and mental health.

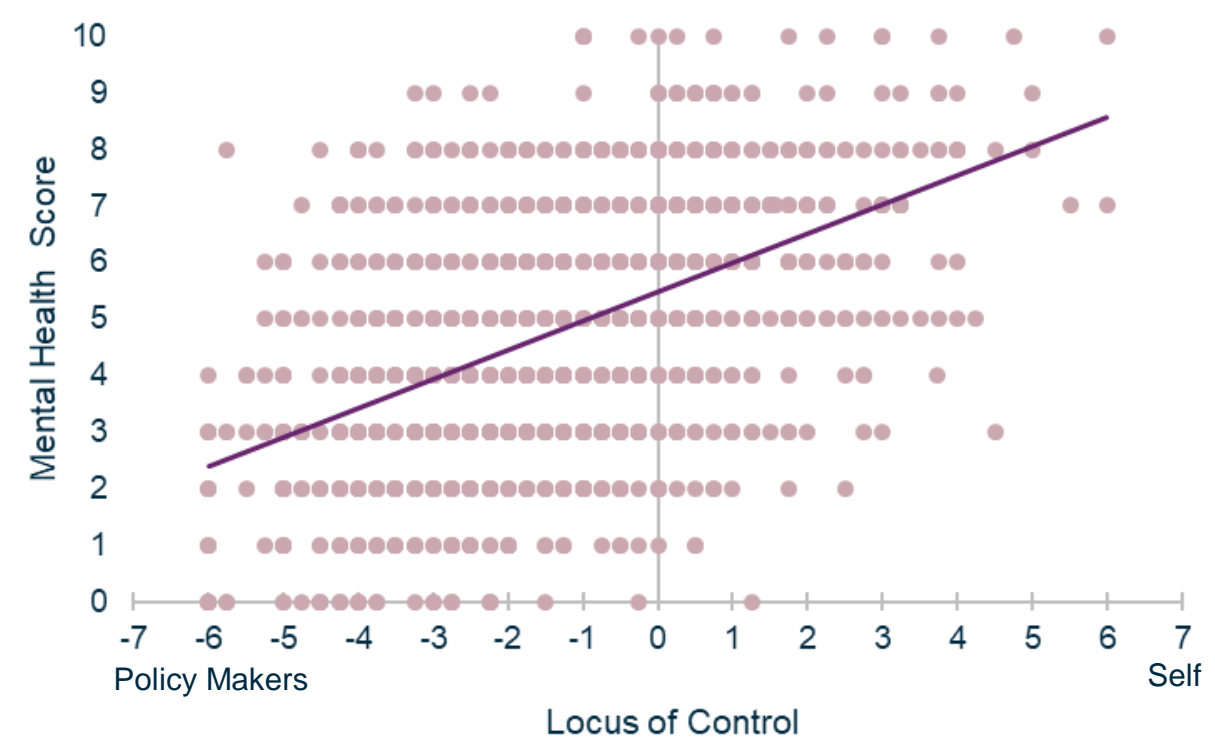

\section{Feeling valued}

Finally, we explored the extent to which respondents felt valued by policy makers. Just $16 \%$ of staff reported feeling valued. In contrast, over half of respondents $(55 \%)$ indicated that they did not feel valued. Respondents who felt valued by policy makers had better mental health and wellbeing than those who did not. For example, we asked respondents whether they thought that policy makers saw them as important. Respondents who agreed had 
higher mental health scores (6.4 out of 10$)$ than respondents who did not think policy makers saw them as important (3.6 out of 10$)$.

\section{Practice and Policy Implications}

This report, alongside other research, suggests that rates of poor mental health and wellbeing are high amongst UK university staff. In the present survey, about one-in-two staff members appears to be at risk of poor mental health. This has significant repercussions both in terms of the human cost and in terms of its economic impact on a sector that contributes $2.9 \%$ of UK GDP and supports 940,000 jobs (Oxford Economics, 2017).

The coronavirus pandemic put additional pressure on already stretched staff resources to provide student-facing services. The present survey suggests that a sizable number of staff members struggled over the course of the pandemic and are suffering from chronic stress and exhaustion.

The present survey also unveiled some entrenched inequalities. Staff with an ethnic minority or low (subjective) social status background, women staff members, staff on fixed term contracts, and staff with caring responsibilities were all at greater risk of poor mental health. This suggests that as university communities we need to double down on our efforts to create an inclusive environment for all. The Athena Swan Charter and the Race Equality Charter may provide a powerful lever to encourage us to reduce the discrepancies in mental health that we see amongst different staff groups.

The present survey highlights ways in which institutional leaders and policy makers may be able to stem the tide of poor mental health and wellbeing in the higher education sector. As we enter new phases of the coronavirus pandemic, we would do well as university communities to consider how we can foster a sense of inclusion and connectedness amongst colleagues. Of course, this needs to be combined with a manageable workload given that chronic stress triggers burnout, which in turn is associated with avoidance and withdrawal (e.g., Volpone, \& Avery, 2013).

One factor that is perhaps less well explored is that of staff members' perceptions of the actions and views of policy makers. Successive higher education policies have created conditions that have led to an erosion of staff remuneration, fierce competition, and, recently, redundancies (Fazackerley, 2021, January 22; Musselin, 2018; UCEA, 2019). Coupled with this is a discourse that is pitting universities against the public with claims such as "Britain has had enough of experts" (Mance, 2016, June 3), and "young people have been taken advantage of" (Coughlan, 2020). The present survey highlights the potential repercussions of these recent trends, and the importance of university staff feeling valued. 
While policy makers and university leaders have an important role to play, we have noted earlier that the current status quo is the result of a range of factors, including but not limited to working cultures and entrenched working practices. The situation can only be resolved through policy-makers and all members of the higher education community working together to prioritise staff and student welfare.

Some milestones have been achieved recently. For example, Universities UK (UUK) published the Mentally Healthy Universities framework advocating a whole university approach to mental health and wellbeing, calling on universities to make mental health a strategic priority (de Pury \& Dicks, 2020). It is important to note that a whole system approach implies that mental health and wellbeing underpins all university policies and practices, and as such, goes beyond staff (and students) taking responsibility of their own wellbeing and making use of opportunities for self-care. The University Mental Health Charter developed by Student Minds also incorporates staff wellbeing as one of 18 themes for which the charter provides principles of good practice (Hughes \& Spanner, 2019). The present report highlights the timeliness and importance of adopting those principles and making the mental health of staff and students a strategic priority.

Overall, this report has documented high levels of poor mental health and wellbeing among university staff. Given the consequences of poor health and wellbeing on productivity and performance (Ford et al., 2011), this may have significant repercussions for the UK university sector, and society more broadly. In publishing this report, we hope institutional leaders, policy makers, and university communities will take remedial action and work together constructively to improve the mental health and wellbeing of university staff. 


\section{Useful Contacts}

If you have been affected by the issues raised in this report, the following places can provide help or advice:

- If you work at a university, your employer will likely provide welfare, counselling and/or occupational health services that you can access.

- Your GP can provide help and support, and can refer you to specialist NHS services such as talking therapies and counselling.

- The NHS website provides information on a variety of mental health conditions, and details how you can refer yourself for talking therapies or counselling (www.nhs.uk/conditions/stress-anxiety-depression/).

- Samaritans provides confidential emotional support if you are experiencing feelings of distress or despair. Call free on 116123 or visit www.samaritans.org. 


\section{References}

Barkhuizen, N., Rothmann, S., \& van de Vijver, F. J. R. (2014). Burnout and work engagement of academics in higher education institutions: Effects of dispositional optimism. Stress and Health, 30(4), 322-332. https://doi.org/10.1002/smi.2520

Bosma, H., Brandts, L., Simons, A., Groffen, D., \& van den Akker, M. (2015). Low socioeconomic status and perceptions of social inadequacy and shame: Findings from the Dutch SMILE study. European Journal of Public Health, 25(2), 311-313. https://doi.org/10.1093/eurpub/cku212

Chen, B., Covinsky, K., Cenzer, I., Adler, N., \& Williams, B. (2012). Subjective social status and functional decline in older adults. Journal of General Internal Medicine, 27, 693699. https://doi.org/10.1007/s11606-011-1963-7

de Pury, J., \& Dicks, A. (2020). Stepchange: Mentally healthy universities. Universities UK. https://www.universitiesuk.ac.uk/policy-and-analysis/reports/Documents/2020/uukstepchange-mhu.pdf

Dougall, I., Weick, M., \& Vasiljevic, M. (2021). Social class and wellbeing among staff and students in higher education settings: Mapping the problem and exploring underlying mechanisms. PsyArXiv. https://doi.org/10.31234/osf.io/f7wmt

Erickson, M., Hanna, P., \& Walker, C. (2020). The UK higher education senior management survey: A statactivist response to managerialist governance. Studies in Higher Education, 1-18. https://doi.org/10.1080/03075079.2020.1712693

Fazackerley, A. (2021, January 22). 'Dispicable in a pandemic': Fury as UK universities plan job cuts. The Guardian.

https://www.theguardian.com/education/2021/jan/22/despicable-in-a-pandemic-furyas-10-uk-universities-plan-job-cuts

Ford, M. T., Cerasoli, C. P., Higgins, J. A., \& Decesare, A. L. (2011). Relationships between psychological, physical, and behavioural health and work performance: A review and meta-analysis. Work \& Stress, 25(3), 185-204. https://doi.org/10.1080/02678373.2011.609035

Guthrie, S., Lichten, C. A., Van Belle, J., Ball, S., Knack, A., \& Hofman, J. (2017). Understanding mental health in the research environment: A rapid evidence assessment. RAND Health Quarterly, 7(3), 2. https://pubmed.ncbi.nlm.nih.gov/29607246

Hughes, G., \& Spanner, L. (2019). The University Mental Health Charter. Student Minds. https://www.studentminds.org.uk/uploads/3/7/8/4/3784584/191208 umhc artwork.pd f 
Jia, R., Ayling, K., Chalder, T., Massey, A., Broadbent, E., Coupland, C., \& Vedhara, K. (2020). Mental health in the UK during the COVID-19 pandemic: Cross-sectional analyses from a community cohort study. BMJ open, 10(9), 1-14.

https://doi.org/10.1136/bmjopen-2020-040620

Kinman, G. (2014). Doing more with less? Work and wellbeing in academics. Somatechnics, 4, 219-235. https://doi.org/10.3366/soma.2014.0129

Kinman, G., Jones, F., \& Kinman, R. (2006). The well-being of the UK academy, 1998-2004. Quality in Higher Education, 12(1), 15-27. https://doi.org/10.1080/13538320600685081

Kinman, G., \& Wray, S. (2013). Higher stress: A survey of stress and well-being among staff in higher education. University and College Union (UCU). https://www.ucu.org.uk/media/5911/Higher-stress-a-survey-of-stress-and-well-beingamong-staff-in-higher-education-Jul-13/pdf/HE stress report July 2013.pdf

Mance, H. (2016, June 3). Britain has had enough of experts, says Gove. Financial Times. https://www.ft.com/content/3be49734-29cb-11e6-83e4-abc22d5d108c

Morrish, L. (2019). Pressure Vessels: The epidemic of poor mental health among higher education staff. Higher Education Policy Institute London (HEPI). https://www.hepi.ac.uk/2019/05/23/pressure-vessels-the-epidemic-of-poor-mentalhealth-among-higher-education-staff/

Musselin, C. (2018). New forms of competition in higher education. Socio-Economic Review, 16(3), 657-683. https://doi.org/10.1093/ser/mwy033

ONS. (2021). Coronavirus and the social impacts on Great Britain. Office for National Statistics.

https://www.ons.gov.uk/peoplepopulationandcommunity/healthandsocialcare/healtha ndwellbeing/datasets/coronavirusandthesocialimpactsongreatbritaindata/current

Oxford Economics. (2017). The Economic Impact of Universities in 2014-15. https://www.universitiesuk.ac.uk/policy-and-analysis/reports/Documents/2017/theeconomic-impact-of-universities.pdf

Padilla, M. A., \& Thompson, J. N. (2016). Burning out faculty at doctoral research universities. Stress and Health, 32(5), 551-558. https://doi.org/10.1002/smi.2661

Shin, J. C., \& Jung, J. (2014). Academics job satisfaction and job stress across countries in the changing academic environments. Higher Education, 67(5), 603-620. https://doi.org/10.1007/s10734-013-9668-y

Tytherleigh, M. Y., Webb, C., Cooper, C. L., \& Ricketts, C. (2007). Occupational stress in UK higher education institutions: A comparative study of all staff categories. Higher Education Research \& Development, 24(1), 41-61.

https://doi.org/10.1080/0729436052000318569 
UCEA. (2019). Real-terms change in the New JNCHES pay spine. Universities and Colleges Employers Association. https://www.ucea.ac.uk/library/stakeholder-briefings/

Watts, J., \& Robertson, N. (2011). Burnout in university teaching staff: A systematic literature review. Educational Research, 53(1), 33-50.

https://doi.org/10.1080/00131881.2011.552235 